Optimizing the influence of social norms interventions: Applying social identity insights to motivate residential water conservation

Word Count: 10417 (including references) 


\begin{abstract}
Social norms-based interventions offer a promising avenue to encourage proenvironmental behavior change. From a social identity perspective, it is argued that social norms communications will be maximally effective when they are tied to salient group memberships and supportive ingroup norms are communicated. Across four studies conducted in a water scarce region in England we demonstrate that a water conservation ingroup norms appeal encourages a shift in behavioral intentions and behavior. We provide initial evidence of the efficacy of the appeal against an information-only message (Study 1) and the mediating role of perceived ingroup norms (Study 2). Across two randomized control field trials, we find the appeal is more effective than a general social norms appeal (Study 3) and that sign-ups to a water-savings program significantly increase when the appeal is integrated into existing promotional materials (Study 4). We conclude by discussing how these insights can offer new perspectives on proenvironmental behavior change.
\end{abstract}

Keywords: Social identity, Residential water conservation, Social norms, Ingroup norms, Group identification, Behavior change intervention 


\section{Optimizing the influence of social norms interventions: Applying social identity insights to motivate residential water conservation}

In regions that experience water scarcity, the impacts can be insidious and far-reaching. The World Economic Forum (2015) declared that water crises were the top global risk in terms of impact. Within the UK, water shortages are recognized as one of the greatest climate-change related threats (Committee on Climate Change, 2016). Ensuring a sustainable water supply requires a multifaceted approach. This will become increasingly important as demand for water continues to rise. In the residential sector alone, demand is projected to increase by $30 \%$ by 2050 (OECD, 2012). Behavioral-based approaches to encourage water conservation can form an integral part of demand reduction strategies. However, far less attention has been paid to investigating water-related interventions in comparison to other residential interventions surrounding energy and recycling (Fielding et al., 2013; Gregory \& Leo, 2003). In the present research, we demonstrate how a social identity approach can be applied to develop more effective and better-targeted behavior change interventions for reducing residential water demand.

\section{The Social Influence Approach to Proenvironmental Behavior Change}

Traditionally, public environmental campaigns have been formulated around the assumption of a knowledge deficit; the belief that suboptimal behavior results from lack of knowledge (Burgess, Harrison, \& Filius, 1998; Schultz, 2002). Applied to water conservation, the knowledge deficit model would predict that individuals might not conserve water because they lack sufficient knowledge about the severity of water shortages or effective actions that can be undertaken. However, evidence of the effectiveness of 'save water' campaigns is scare (Syme, Nancarrow, \& Seligman, 2000). While information-based approaches may increase knowledge, increased knowledge does not necessarily translate into behavior change (Abrahamse, Steg, Vlek, \& Rothengatter, 2005; Geller, Bechtel, \& 
Churchman, 2002). Instead, research suggests it may be more effective to appeal to people's social motivations and provide information regarding the activities of other people. 'Social norms' refer to a set of beliefs about what the majority of other people do, or approve of doing (Cialdini \& Trost, 1998).

An emerging literature suggests that social norms-based interventions may offer a promising avenue for encouraging water conservation. Fielding and colleagues (2013), for instance, demonstrated that providing social norms information outlining the water saving behavior undertaken by water efficient households and providing personalized feedback led to a reduction in consumption in a water scarce region in Australia. Similarly, Schultz and colleagues (2016) showed that personalized water consumption feedback coupled with normative information about the usage of other households led to a reduction in household water use compared to an information-only or no-treatment control condition. And, although null results have been observed (e.g. Kurz, Donaghue, \& Walker, 2005), a recent review of the effectiveness of smart-meter based consumption feedback concluded that coupling feedback with normative information about the usage of other households can effectively encourage water conservation (Sønderlund, Smith, Hutton, Kapelan, \& Savic, 2016). The present research seeks not only to expand the empirical evidence base for social-norms interventions as a means of reducing water demand, but also to consider how the effectiveness of such interventions can be maximized by drawing on insights from the social identity perspective.

\section{The Social Identity Perspective: Moving from Social Norms to Ingroup Norms}

The social identity approach incorporates two interrelated theories - social identity theory (Abrams \& Hogg, 1988; Tajfel \& Turner, 1979) and its extension, self-categorization theory (Turner, Hogg, Oakes, Reicher, \& Wetherell, 1987) - which seek to explain how 
individuals' attitudes, emotions and behaviors are shaped by the groups to which we belong. According to the social identity approach, individuals define themselves not only in terms of their personal traits (e.g. 'I am athletic'), but also in terms of their group memberships (e.g. 'I am Australian'). This group-based definition of the self forms an individual's social identity. When we think about ourselves in terms of a specific group membership, or a group membership is becomes salient in a certain situation, that social identity forms the basis for self-definition. Rather than see ourselves as unique individuals defined in terms of idiosyncratic personal attributes, we see ourselves as an exemplar of the group defined in terms of the same group-defining attributes as other members of that group. This cognitive redefinition of the self is known as depersonalization, or self-stereotyping.

According to the social identity approach, social influence operates on the basis of salient group identities through a process of referent informational influence (Turner et al., 1987; Turner, Wetherell, \& Hogg, 1989) - the theory of group influence under the social identity approach. When we self-categorize as members of a particular group, we answer the question, 'Who am I?' in terms of the characteristics that we share with other group members. We also answer the question, 'What should I do?' with reference to the ingroup stereotype. The process of depersonalization assimilates the self to the group prototype and thus, an individual's behavior becomes group-based and guided by the norms of the social category or group. Moreover, because the norms are internalized as part of the individual's self-concept and are linked to his or her membership to that group, the norm may exert influence over behavior even in the absence of other group members (Abrams \& Hogg, 1990). Identification-based conformity is not a process of surface compliance, but of genuine internalization of a group's attitudes, emotions, and behaviors as one's own.

While the social identity approach was originally developed to understand prejudice and intergroup relations, researchers have recently called for a social identity analysis of 
proenvironmental behavior (Fielding \& Hornsey, 2016; Fritsche, Barth, Jugert, Masson, \& Reese, 2017). The value of the social identity approach for behavior change interventions is that it serves to clarify which 'others' will influence behavior. From this perspective, norms are tied to a specific group and exert their influence because that specific group is behaviorally-relevant. Experimental research has supported this claim, typically through manipulations of ingroup norms or stereotypes that impact on people's attitudinal and behavioral responses (e.g. Hogg \& Turner, 1987; Simon \& Hamilton, 1994; Terry, Hogg, \& McKimmie, 2000; Turner \& Reynolds, 2008). Mackie and Cooper (1984) for instance, asked participants to listen to a taped group discussion and were either given no information about their relationship to the group on the tape (the uncategorized condition) or told that they were going to join it (the categorized condition). When asked to express their own views, only the judgements of the categorized participants showed conformity to the normative position of the group. Research also demonstrates that classic social influence effects (e.g. Asch, 1955; Sherif, 1936), do not occur when the source of social influence is an outgroup member (Abrams, Wetherell, Cochrane, Hogg, \& Turner, 1990), and individuals will actively contrast away from the stereotype of the outgroup in intergroup comparative contexts (e.g. Doosje, Haslam, Spears, Oakes, \& Koomen, 1998; Rabinovich, Morton, Postmes, \& Verplanken, 2012). When it comes to developing environmental behavior change tools, the implication is that rather than simply communicating that the majority of 'others' are undertaking or approve of a given behavior, communications should focus specifically on 'ingroup others'.

Some existing findings related to proenvironmental behavior change can be considered through the lens of the social identity approach. In an experiment aiming to increase towel reuse in a hotel setting, Goldstein and colleagues (2008) found that normative information was most influential when it focused specifically on 'other hotel guests who stayed in this room', as opposed to the broader category of 'fellow guests'. Similarly, in an investigation of 
household energy consumption in California, Nolan and colleagues (2008; cited in Griskevicius, Cialdini, \& Goldstein, 2008) found that the influence of perceived social norms grew stronger the closer and more similar the referent group was to the individual. The decision to conserve energy was most powerfully influenced by the norms of other residents in one's specific community, followed by other people in their city, followed by other Californians generally. The social identity perspective suggests the effectiveness of these messages relates to the perception that 'others' who stayed in the hotel room previously, or who live in one's local community represent fellow ingroup members.

Evidence of the importance of ingroup norms in promoting proenvironmental behaviors is also suggested by research examining the determinants of behavior within a theory of planned behavior framework (TPB; Ajzen, 1985, 1991). The TPB posits that behavior is most proximally predicted by behavioral intentions, which in turn are predicted by attitudes, perceived behavioral control, and subjective norms. Within the original formation of the TPB, subjective norms refer to the approval of 'important others'. The integration of social identity concepts has more recently demonstrated how focusing on specific referent group norms, rather than the expectations and desires of generalized others, can increase the models' predictive validity. For example, Terry, Hogg, and White (1999) found that perceived ingroup norms predicted intentions to engage in recycling behaviors, beyond standard TPB variables. Similarly, in a sample of farmers, Fielding, Terry, Masser, and Hogg (2008) showed ingroup norms influence intentions to engage in sustainable agricultural practices.

Research has recently provided some direct support for the ability of an ingroup norm appeal to promote household water conservation. In a field study conducted in California by Seyranian, Sinatra and Polikoff (2015; see also Seyranian, 2014) households were provided with a short communication that linked general proenvironmental behaviors to a local city 
identity using high levels of inclusive language to portray that acting proenvironmentally is a normative component of 'who we are' and 'what we stand for' as a city (p. 85). The intervention successfully reduced household water consumption compared to households exposed to information alone. No discernible difference was found between the appeal that focused on a specific referent group and a standard social norms appeal, however this may be because the social norms condition was delivered in conjunction with comparative water usage feedback. In line with the referent informational influence process, an ingroup norms appeal should be maximally effective when it is framed in reference to the ingroup. Therefore, it is important to test an appeal that frames water conservation behavior as being normative of the targeted ingroup (e.g. residents, rather than the city government). In other evidence, Mallett and Melchiori (2016) recently found that a campaign that described members of a university community as water savers led to a reduction in water consumption in the university halls of residence. No comparison was made to a standard social-norms approach however, and the campaign contained other persuasive elements (including free gifts and water-saving pledges). It was therefore not possible to isolate the effect of delivering ingroup-normative information.

\section{The Present Research}

The current package of studies aims to provide a comprehensive test of the impact of an ingroup norms appeal on water conservation behavior. Existing research demonstrates the power of normative messages for encouraging proenvironmental behavior (e.g. Allcott, 2011; Nolan, Schultz, Cialdini, Goldstein, \& Griskevicius, 2008; Schultz, Nolan, Cialdini, Goldstein, \& Griskevicius, 2007), and water conservation behavior specifically (e.g. Fielding et al., 2013; Schultz et al., 2016). Given the potential for social norms interventions to contribute to the water demand-management tool-kit, it has now become important to understand whether there are ways to optimize the approach. Utilizing social identity insights 
(Tajfel \& Turner, 1986; Turner et al., 1987), it is predicted that messages providing a group context and source - highlighting a social identity while promoting ingroup norms favoring water conservation behavior (an ingroup norms appeal) - will encourage corresponding behavior change. Here, we aim to empirically test an ingroup norms appeal, in which the targeted social identity is made salient (e.g. a local region; city; or community), and this is then tied to water conservation efforts by stressing that this behavior is ingroup normative and defines and characterizes the group identity.

Our investigation is organized around four central questions (and experiments): 1) Are ingroup norm appeals more effective than information alone? 2) Are intervention effects driven by changes in perceived ingroup norms? 3) Are ingroup norm appeals more effective than general social norms appeals? 4) Can ingroup norms interventions impact actual behavior? This research was conducted in Norfolk in the East of England, a region prone to water stress (Committee on Climate Change, 2016).

\section{Study 1 - Are ingroup norm appeals more effective than information alone?}

Study 1 aimed to provide initial evidence for the ability of an ingroup norms appeal to increase individuals' intentions to engage in water conservation behaviors. We compared the effectiveness of this approach against two control conditions - an information-only control and a no-treatment control. The information-only control allowed the effects of receiving information about the importance of saving water to be separated from the effects of social information that suggests this behavior is normative of one's social group. The no-treatment control served as a baseline and a test of the effectiveness of information provision alone.

\section{Participants and Design}

A total of 143 participants were recruited from a public square at a university in the East of England. The sample consisted of 100 females and 43 males, aged between 18 and 44 
$(M=21.82, S D=4.17)$. No exclusions were made. Participants were randomly assigned to one of three conditions in a between-subjects design: ingroup norms appeal $(n=46)$; information-only $(n=50)$; or no-treatment control $(n=47)$. Responses were collected via pen-and-paper-based questionnaires. Ethics approval from the university's ethics board was granted for each experiment in this paper.

\section{Procedure}

Following the informed consent process, participants were presented with the experimental manipulations. Participants in the information only condition were presented with a short text urging the importance of saving water around the home. Specifically, participants in the information-only condition read:

Save Water. Although water may seem abundant, fresh water is a limited resource. You can do your bit to save water around the house - in the kitchen, in the bathroom, and while washing clothes.

In the ingroup norms condition, this same information was augmented with normative information. The university group represented the referent group for the norms manipulation. The intervention urged not just the importance of saving water, but that this behavior was ingroup normative and embedded in the university student identity. A graphic logo related to the university was included to increase the salience of this group identity (see: Seyranian, 2014; Seyranian et al., 2015). The text incorporated both injunctive and descriptive supportive norms, consistent with findings from prior research (e.g. Cialdini, Kallgren, \& Reno, 1991; Schultz, Nolan, Cialdini, Goldstein, \& Griskevicius, 2007) demonstrating that the effectiveness of social norms messaging can be enhanced if injunctive and descriptive norms are both positive and supportive of the targeted behavior. Specifically, participants in the ingroup norms condition read: 
UEA Students Save Water. Although water may seem abundant, fresh water is a limited resource. As UEA students, saving water and caring for the environment is part of who we are. We're proud to be water savers and we do our bit to save water around the house - in the kitchen, in the bathroom, and while washing clothes.

Participants in the no-treatment control condition did not read any information but went immediately on to complete the dependent measure. The dependent variable was participants' intentions to engage in water conservation. Participants indicated how likely they were to engage in various water-saving behaviors over the next few weeks (from $1=$ not at all likely to $7=$ very likely). Behaviors included: 'Turn off the tap when brushing teeth' and 'Whenever possible, set the shower pressure to a low, or medium, rather than high level'. These items were selected from a range of tips offered by the region's water utility company (Anglian Water, 2015) and were recognized as being effective approaches which were unrestrained by context (e.g. it did not matter if respondents had a garden or not, or were able to install water efficient devices or not). Items were combined into a composite index of behavioral intentions $(\alpha=.66)$. To conclude the experiment, participants provided demographic information and were thanked and debriefed.

\section{Results and Discussion}

A univariate ANOVA tested the difference in water saving intentions between conditions. A significant omnibus effect was observed, $F(2,140)=10.61, p<.001, \eta^{2}=.13$. Intentions followed the predicted step-wise trend. A Bonferroni post hoc analysis revealed that intentions were significantly higher in the ingroup norms condition $(M=5.28, S D=0.85)$ compared to the no-treatment control condition $(M=4.48, S D=0.91)$, Mdiff $=0.79,95 \% \mathrm{CI}$ $[0.38,1.20], p=<.001$, and marginally higher than the information-only condition $(M=$ $4.90, S D=0.73)$, diff $=0.38,95 \%$ CI [-.03, 0.79], $p=.080$. Intentions were significantly 
higher in the information-only condition compared to the control condition, Mdiff $=0.41$, $95 \%$ CI [0.04, 0.82], $p=.047$ (see Figure 1).

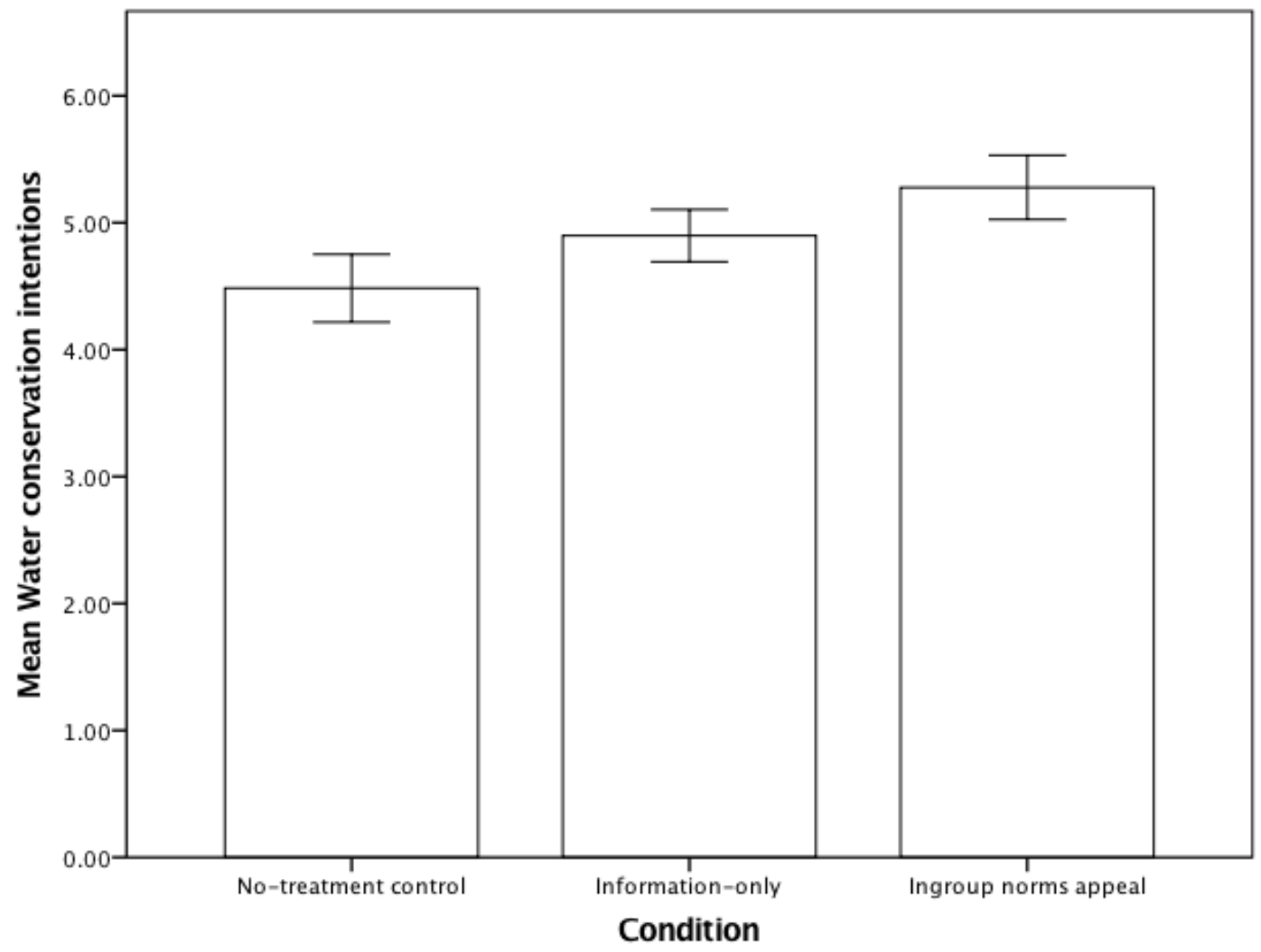

Error Bars: $95 \% \mathrm{Cl}$

Figure 1. Mean water conservation intention scores across the three conditions: no-treatment control; information-only; and ingroup norms appeal

Study 1 provided initial evidence for the efficacy of an ingroup norms appeal by comparing the effectiveness of this approach to an information-only and no-treatment control. We do find evidence that providing information about the importance of saving water increased intentions to do so compared to baseline. Although the difference between the information-only condition and the ingroup norms appeal was not statistically significant $(p=.068)$, the general trend suggests it may be even more effective to frame this information 
as being normative of one's social group, consistent with a social identity-based process (Hogg \& Turner, 1987; Turner, 1982).

\section{Study 2 - Are intervention effects driven by changes in perceived ingroup norms?}

According to the social identity approach, the process through which representations of the ingroup (e.g. norms, stereotypes) become the basis for behavior is internalization; people internalize the norms and values of the groups they belong to by incorporating that social identity as an aspect of their self-concept (Tajfel \& Turner, 1986; Turner et al., 1987). Congruent with the referent informational influence process, if people learn of a normative attitude or behavior of the ingroup, they will use this normative information as a cue to guide their own behavior. This framework suggests our intervention approach is effective because it increases perceptions of ingroup norms surrounding water conservation, which then subsequently act as a guide for individual's behavior as a group member. Study 2 sought to provide an empirical test of this hypothesis. We expected that the intervention would change individuals' behavioral intentions, mediated by changes in perceived ingroup norms.

\section{Participants and Design}

Members of the public were approached in the center of Norwich, a city in the East of England. A total of 126 volunteers were recruited over a two-day period. The referent group for the experimental manipulation was the residential city and participants were asked to confirm that they lived in Norwich before beginning the survey. Two participants were removed from the analysis because they were not city residents. The final sample consisted of 124 individuals (62 females and 62 males) aged between 18 and $86(M=40.07, S D=15.74)$. Having established the effects of the ingroup norms intervention in comparison to an information-based campaign in Study 1, the design was refined in Study 2 to focus only on the comparison between the ingroup norms intervention and a no-treatment control. 
Participants were randomly assigned to either the intervention condition $(n=63)$ or the control condition $(n=61)$ in a between-subjects design.

\section{Procedure}

The intervention text was adapted from that used in Study 1 with several refinements. Using survey data collected as part of a pre-test $(n=40)$, we identified several water-saving actions that people from the local region commonly reported performing. This helped to create a picture of supportive ingroup norms surrounding water conservation (behaviors included: waiting until there is a full load of washing before beginning a wash cycle; turning off taps if they haven't been shut off properly; and turning off the tap when brushing teeth). This information was also reinforced by a quote ostensibly from a local resident, expressing their support for water conservation efforts. To help incentivize participation, respondents were given a free magnet that displayed a cartoon water droplet figure and the message 'Norwich Saves Water'. Participants in the no-treatment control condition also received a free magnet, which contained just the illustration and no message.

Participants then completed the dependent variables. Perceived ingroup norms were measured with four items, including 'Members of the Norwich community think that saving water is important', and 'Most members of the Norwich community try to conserve water' (from $1=$ strongly disagree to $7=$ strongly agree, $\alpha=.86$ ). Following the norm items, six items measured participants' intentions to engage in water conservation behaviors. Items were adapted from Study 1. Participants indicated on a seven-point scale how likely it was that they would perform each behavior over the next few months (from $1=$ not at all likely to $7=$ very likely). To reduce the possibility of demand characteristics, we did not include any of the behaviors specifically mentioned in the experimental text. New items included: 'Try to cook food with as little water as possible' and 'Try to soak pots and pans 
instead of letting water run when washing dishes' $(\alpha=.86)$. To conclude the experiment, participants provided demographic information and were thanked and debriefed.

\section{Results and Discussion}

In line with predictions, an independent samples $t$-test confirmed that water conservation intentions were significantly higher in the intervention condition $(M=5.59, S D$ $=1.00)$, compared to the control $(M=4.96, S D=1.32)$, Mdiff $=0.63,95 \%$ CI $[-1.04,-.21]$, $t(122)=3.00, p=.003, d=.54($ see Figure 2$)$.

A second $t$-test examined the direct effect of the intervention on perceived ingroup norms. Water conservations ingroup norms were marginally higher in the intervention condition $(M=4.34, S D=1.09)$, relative to the control $(M=3.99, S D=1.09)$, Mdiff $=0.35$, $95 \%$ CI $[-74, .03], t(122)=1.810, p=.073, d=.33($ see Figure 2$)$.

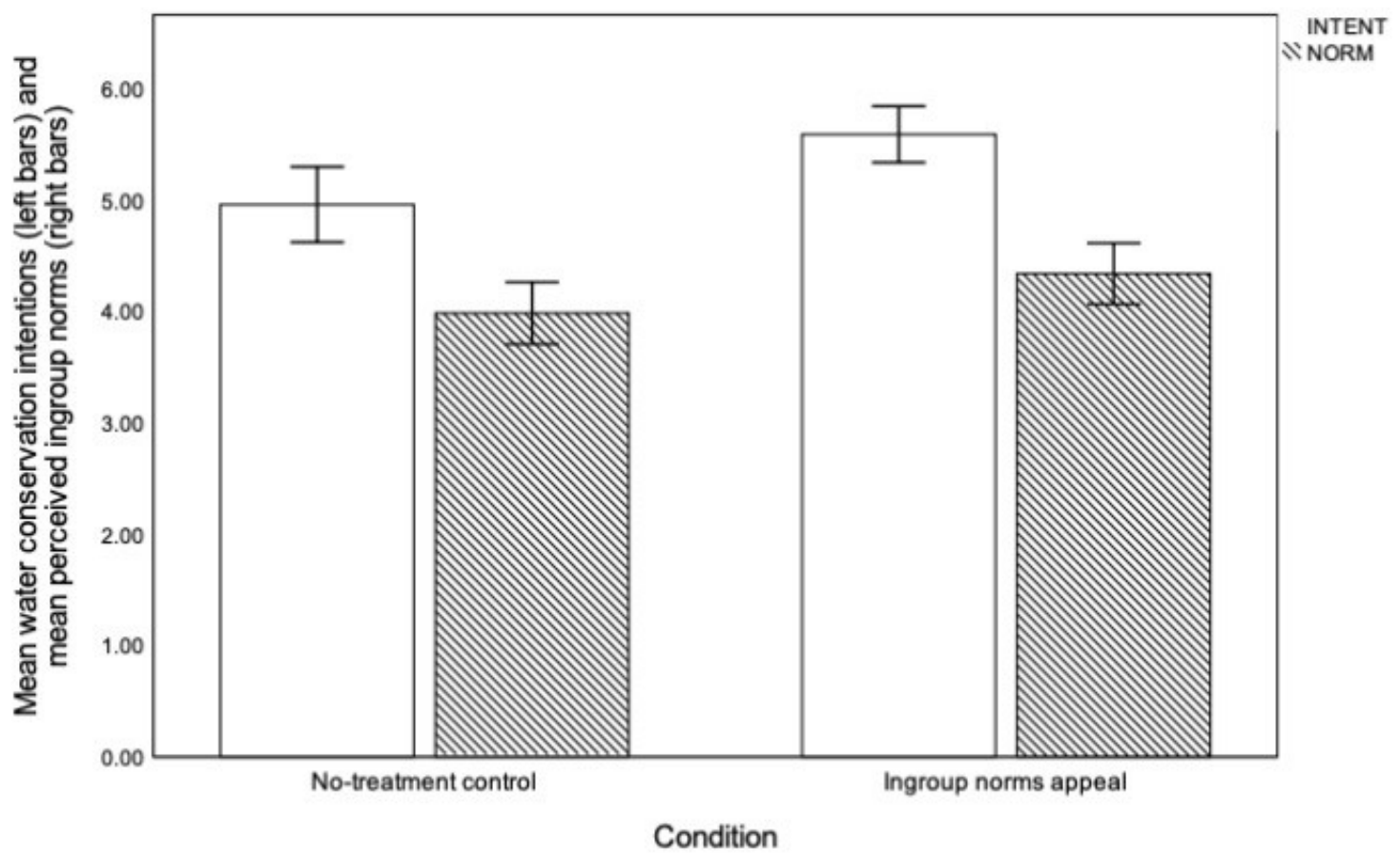

Figure 2. Mean water conservation intentions (left bars; no pattern) and perception of ingroup water conservation norm (right bars; pattern) scores across the two conditions: notreatment control and ingroup norms appeal 
A mediation analysis was then conducted to investigate whether the effect of the intervention on behavioral intentions could be explained by an increase in perceived water conservation ingroup norms. The analysis was conducted using bootstrapped tests of the indirect path (based on 5,000 bootstrapped resamples), with effects calculated using Hayes (2013) PROCESS macro (Model 4). Experimental condition was entered as the independent variable $(0=$ control, $1=$ intervention $)$, ingroup water conservation norms as the mediator, and intentions to engage in water conservation behaviors as the dependent variable. The mediation model is depicted in Figure 3. In line with expectations, there was a significant indirect effect of condition on intentions through ingroup norms, $b=.14, S E=.08$, with a bias corrected confidence interval of .0025 to .3223 . That is, the intervention led to perceptions that water conservation was ingroup normative, which in turn lead to higher intentions to engage in water conservation behaviors.

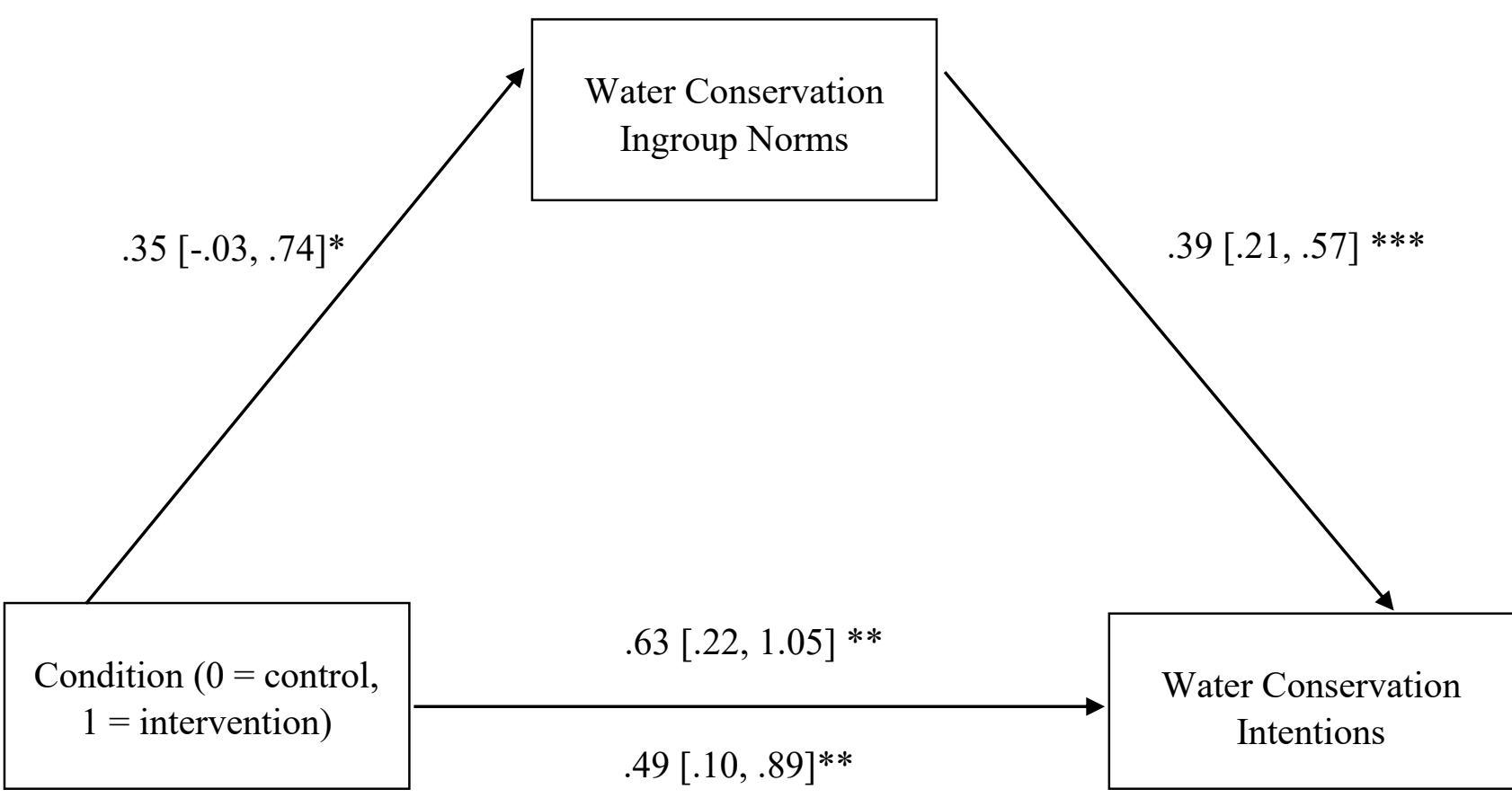

Figure 3. Mediational model of the relationship between the intervention condition and water conservation intentions through ingroup water conservation norms (Study 2)

Note: Path estimates represent unstandardized coefficients. $95 \%$ confidence intervals presented in parentheses.

$* p<.10 * * p<.05 * * * p<.001$ 
The results of Study 2 provide further insight into the efficacy of our ingroup norms appeal and confirm the underlying mediational process. Results suggest that individuals internalized the intervention material as normative information about the ingroup, and subsequently intended to act in line with those norms. Interestingly the mediation was only partial, suggesting that other processes are also at play. It is possible, for instance, that communicating supportive ingroup norms surrounding water conservation may also increase perceptions of collective efficacy (e.g. Morton, Rabinovich, Marshall, \& Bretschneider, 2011). If an individual perceives that there is a collective effort to conserve water in their community (e.g. 'many drops will fill the bucket'; Bonniface \& Henley, 2008), they may be more likely to engage in sustainable water behaviors.

\section{Study 3 - Are ingroup norm appeals more effective than general social norms appeals?}

In two studies, we have now provided evidence of the power of an ingroup norms appeal to influence the water conservation behavioral intentions of group members. The strongest test of our approach, however, is to compare it to a standard social norms appeal. Drawing on a social identity perspective, we expect norm adherence to be strongest when norms are tied to specific versus general referents. Study 3 directly tested this assumption. Seyranian and colleagues (2015) previously failed to find evidence of higher levels of behavior change following an ingroup norms intervention compared to a standard social norms intervention (both were effective compared to baselines). However, the actual content of the intervention was different across these two conditions, limiting the ability to make meaningful comparisons. While the ingroup norms intervention involved a short communication constructed with group level rhetoric, the social norms intervention involved personalized water usage feedback which was augmented with information about whether their usage was above or below the neighborhood mean. Moreover, this social norms intervention may have inadvertently tapped into the influence potential of group-level norms 
by referring to the "average home in your neighborhood" (Seyranian et al., 2015, p. 85).

Additionally, in the social identity communication, normative information was provided in reference to the city government, rather than the ingroup members (city residents) per se. In Study 3 we sought to provide a more controlled examination of normative communications that focus on global social norms, compared to those that are informed by the social identity approach and focus specifically on ingroup norms.

A second aim of Study 3 was to test our intervention in the field, focusing specifically on showering behavior. This study was conducted within university halls of residence. We sought to encourage students to shorten their time in the shower by enhancing perceptions of normative support for this behavior. It is recommended that interventions should be designed to target high-impact behaviors (Steg \& Vlek, 2009), and showering accounts for the largest proportion of total household water consumption in the UK (Energy Saving Trust, 2013). At the university where this research was conducted, student accommodation accounts for $64 \%$ of the total water consumed on campus (UEA, 2016). Any reduction in water used in the shower would therefore have clear benefits. It was expected that normative appeals would be most effective when they focus on a specific, behaviorally-relevant referent group, rather than enhancing perceptions of normative support for the behavior across a range of potential reference points.

\section{Participants and Design}

Data was collected from first-year undergraduate participants living in the halls of residence at the same university as used in Study 1. A total of 1019 single occupancy en-suite rooms were available across three residential blocks. Each room was randomly assigned to one of the three conditions in a between-subjects design: ingroup norms; social norms; or control (no-intervention). Rather than manipulating the independent variable at the level of residential block and risk any block-related confounds (e.g. blocks being different in style or 
condition), each of the three residential blocks were divided into subgroups and each subgroup was allocated to one of the three conditions (e.g. Group A across all three residential blocks was allocated to the ingroup norms condition, Group B to the social norms condition, and so forth). Of the 1019 rooms included in the trial (sample size was maximized), a total of 512 questionnaire responses were received from their occupants (50.24\% return rate). The final sample consisted of 303 females, 198 males, one transgender participant, and 10 who did not report their gender. All respondents were in their first-year at university, as reflected by a rather narrow age distribution $(M=19.06, S D=1.31)$. Responses were relatively equally distributed across the ingroup norms intervention condition $(n=193)$; social norms intervention condition $(n=167)$; and the control condition $(n=152)$.

\section{Procedure}

Intervention materials were installed while students were away from the university for Easter break. During this time, members of the university cleaning team went into rooms and placed waterproof stickers bearing the intervention messages in students' en-suite shower cubicles. The intervention text can be seen in Figure 4. The behavior targeted by the intervention was a reduction in shower time by 1 or 2 minutes (translating to 7-14 liters of water per shower). The social norms intervention sought to encourage this behavior by suggesting it represents a common water saving strategy used by other people generally. In the ingroup norms intervention, the normative information was the same, but this time a group context and source was provided. Saving water by reducing time in the shower by one or two minutes was presented as something that was normative amongst other students at the university. An illustration of a university mascot also accompanied the text to increase the salience of the social identity. No sticker was placed in the rooms assigned to the control condition. 


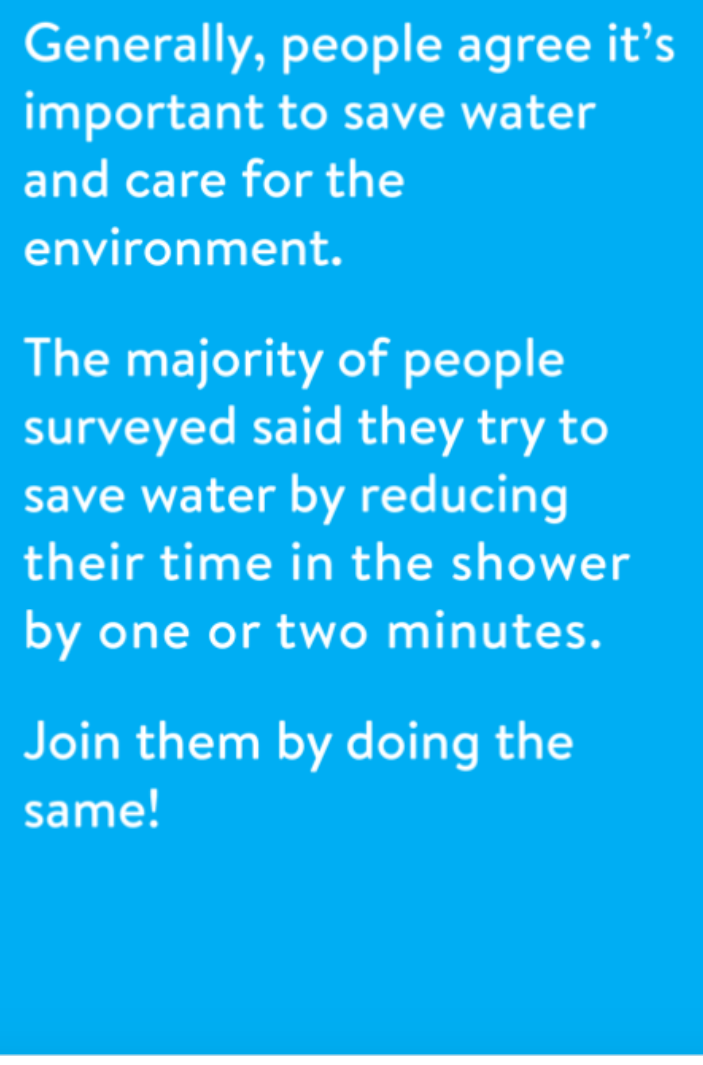

UEA students agree it's important to save water and care for the environment.

The majority of UEA students surveyed said they try to save water by reducing their time in the

shower

by one

or two

minutes.

Join your

fellow UEA

students by

doing the same!
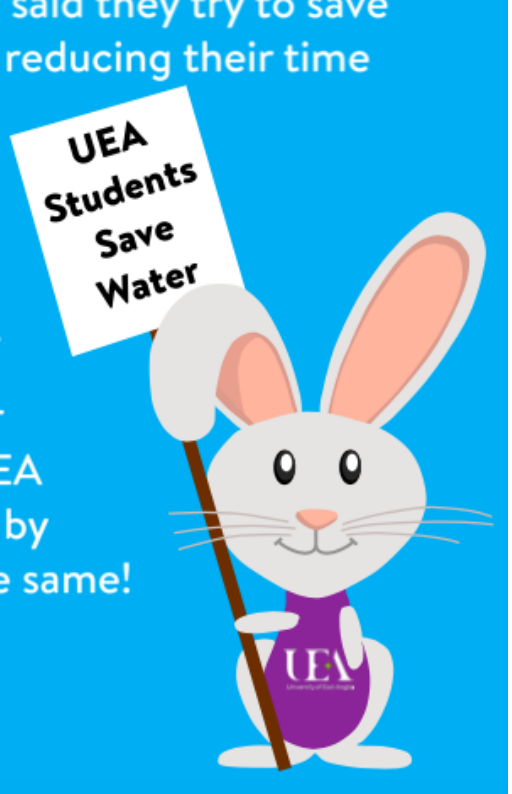

Figure 4. Waterproof stickers used in the social norms condition (left) and the ingroup norms (right) in Study 3.

The intervention period began when students returned to the residences for the spring semester. Two weeks later, members of the university cleaning team left a survey in every room, along with a bag of sweets to incentivize participation. Completed surveys were collected by the cleaning team on their return visits. The principle dependent variable was participants' self-reported shower duration. Participants were asked to estimate how long they spent in the shower, on average, over the last two weeks (post-intervention shower duration), as well as how long they generally spent in the shower, not including the last two weeks (pre-intervention shower duration). By way of a manipulation check, we also 
measured participants' awareness of the stickers that had been placed in their bathroom, "Did you notice a new sign or sticker in your bathroom over the last two weeks?" $(0=$ no, $1=y e s)$.

\section{Results and Discussion}

Manipulation checks. Awareness of the intervention stickers was high across both the social norms intervention condition (94\%), and social identity intervention condition (95.7\%) suggesting participants attended to the intervention material.

Self-reported shower time. A univariate ANOVA was first conducted to confirm that there were no difference between condition on pre-intervention self-reported shower duration, $F(2,511)=.933, p=.394$. To test for intervention effects, an ANCOVA was conducted to determine if there was a difference between conditions on post-intervention self-reported shower duration. Pre-intervention showering time was included as a covariate. Post-intervention shower duration was significantly different between conditions, $F(2,508)=$ $4.74, p=.009, \eta^{2}=.018$. Bonferroni post hoc analysis revealed that the mean increase in post-intervention shower duration (minutes) from the no-treatment control to the general social norms appeal condition was not statistically significant (Mdiff $=.05,95 \%$ CI [-.62, .73], $p=1.00$ ) (see also Table 1). There was a statistically significant increase from the notreatment control to the ingroup norms appeal condition $($ Mdiff $=.73,95 \%$ CI $[.08,1.39], p=$ .022). There was also a statistically significant increase from the general social norms appeal condition to the ingroup norms appeal condition (Mdiff $=.68,95 \%$ CI $[.04,1.32], p=.032)$ (see Figure 5). 
Table 1 Means, Standard Deviations, and Mean Difference of Pre-Intervention and PostIntervention Average Shower Time (Minutes) Per Condition

\begin{tabular}{|c|c|c|c|c|c|}
\hline & \multicolumn{2}{|c|}{ Pre-intervention } & \multicolumn{2}{|c|}{ Post-intervention } & \multirow{2}{*}{$\begin{array}{c}\text { Mean } \\
\text { Difference } \\
M_{\text {Diff }}\end{array}$} \\
\hline & $M$ & $S D$ & $M$ & $S D$ & \\
\hline No-treatment Control & 12.06 & 7.45 & 11.34 & 6.78 & 0.63 \\
\hline General Social Norms & 11.95 & 7.29 & 11.19 & 7.17 & 0.76 \\
\hline Ingroup Norms & 11.14 & 6.27 & 9.82 & 5.49 & 1.32 \\
\hline
\end{tabular}

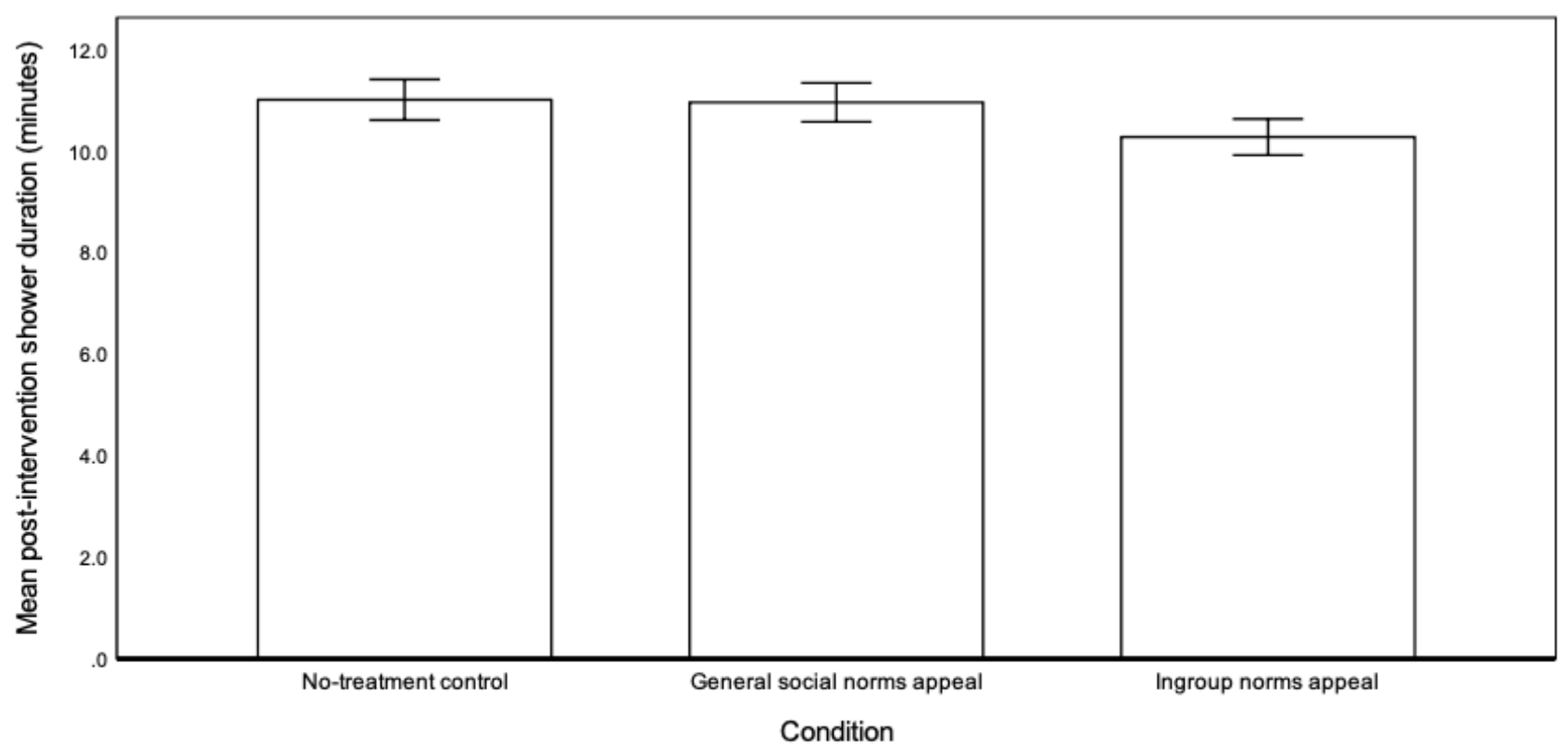

Covariate: Mean pre-intervention shower duration (minutes) $=11.681$

Error bars: $95 \% \mathrm{Cl}$

Figure 5. Mean post-intervention shower duration (minutes) by condition in Study 3. Preintervention shower duration is included as a covariate. 
The results of Study 3 support our reconceptualization of the role of social norms in environmental behavior change interventions. In a field study conducted in university halls of residence, we aimed to encourage individuals to save water by reducing their time in the shower. Our interventions were designed to increase perceptions of normative support for this behavior at either a general societal level, or the group level. As predicted by the social identity perspective (Tajfel \& Turner, 1986; Turner et al., 1987), an ingroup norms appeal was more effective than a standard social norms appeal. Only when the normative information was tied to a contextually-salient group membership did individuals align their behavior to this norm. Results do, however, rely on participants' own estimates of shower duration, which are susceptible to demand characteristics. It is possible that participants may have guessed the experimental hypotheses and adjusted their estimates in accordance with what they believed the experimenter expected of them (i.e. a reduction in shower time over the intervention period). Encouragingly, both intervention conditions were subject to the same demand yet significant reductions were only observed in the ingroup norms condition. Nevertheless, it is important to go on to test the effects of our intervention approach on a direct measure of behavior, beyond self-reports.

\section{Study 4 - Can ingroup norms interventions impact actual behavior?}

Study 4 sought to confirm the effects of an ingroup norms appeal on a direct measure of water conservation behavior. The study was conducted in collaboration with a local water utility company which is responsible for over six million domestic and commercial customers in the East of England. As part of their service, they offer a free residential retrofitting service (the 'Bits and Bobs' program) whereby a plumber visits the customer's property and fits water efficiency devices, including low-flow showerheads and low-flow tap inserts. It is estimated that households save an average of 41 liters per day following the visit (Anglian Water, 2017). Households are currently recruited for the program via a postal letter. In this 
study we tested whether adapting this letter to include an additional ingroup norms appeal would increase the likelihood of households signing up to the program.

\section{Participants and Design}

The study was conducted in Norfolk, England in November, 2016. The sample consisted of all metered households within 34 towns and villages in the southeast of the region. The total sample was 2306 households. Data was not available regarding householdlevel characteristics. Households were randomly assigned to receive either the standard control letter $(n=1158)$, or the intervention letter that contained the ingroup norms appeal $(n$ $=1148)$.

\section{Procedure}

Participants in the control group received a copy of standard, existing letter used by the company. It outlined why saving water was important in the region, the details of the retrofit program, the benefits of signing-up (saving water, energy, and money), and details of how to register. In the intervention condition, this letter was supplemented with an additional social identity appeal, displayed as a banner at the top of the letter (see Figure 6). The referent group for the manipulation was the local county (Norfolk), which encompasses all 34 towns and villages included in the mail-out. The message referred to water-saving ingroup norms and suggested that many other local residents had already signed up for the program. An illustration of a windmill, which is considered an icon of the local area, accompanied the message. All residents were given the opportunity to contact the water utility to register for the program either by telephone, returning an enclosed form, or online. The water utility company collated sign-ups across these platforms and provided the final data six weeks after the letters had been posted. 


\section{Norfolk Saves Water}

Norfolk is a water stressed area, with only a small gap between the amount of water available to us and the amount we all use. We know people in Norfolk care about the environment and saving water.

People from Norfolk are more likely to save water in their homes and gardens. It's why many people in your local community have signed up to receive water-saving devices through our free Bits \& Bobs giveaway. You can do the same!

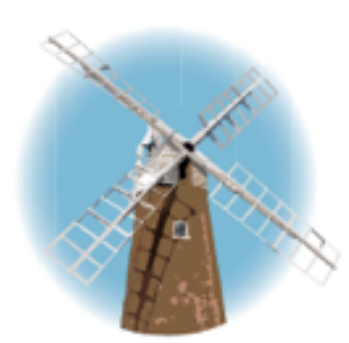

Figure 6. Ingroup norms appeal included at the beginning of customer letters in Study 4.

\section{Results and Discussion}

A chi-squared analysis confirmed that the proportion of households who signed up to the program was significantly higher in the ingroup norms intervention condition, $4.97 \%$, than in the control condition, $2.59 \%, \chi^{2}(1, n=2306)=8.95, p=0.02$. Examination of the odds ratio revealed that households who received the letter with the additional ingroup norms appeal were 1.97 times $(95 \%$ CI $[1.25,3.08])$ more likely to sign-up for the water-saving program than those who received the standard letter.

These results provide further support that ingroup norms messaging can encourage water-conservation efforts. In this study, we collaborated with the region's water utility company to increase sign-ups for a retrofitting program by incorporating an ingroup norms appeal into promotional materials. Sign-up rates were significantly higher amongst households who received our amended letter compared to those who received a standard letter containing no normative information. Measuring sign-ups to a retrofitting program provides a direct measure of water conservation behavior, and increasing participation in such programs is an important aim. Initiatives such as 'Bits and Bobs' can deliver substantial water savings in the residential sector. In this study, overall sign-up rates were low, which speaks to the limitations of unsolicited letters as a communication method (Sinclair, O'Toole, Malawaraarachchi, \& Leder, 2012). However, with the program estimated to deliver an 
average saving of 41 liters per household per day, the increase in the number of sign-ups achieved as a result of this intervention equate to a projected annual savings of over 400,000 litres ${ }^{1 .}$

\section{General Discussion}

The social identity approach (Tajfel \& Turner, 1986; Turner et al., 1987) demonstrates that the attitudinal and behavioral characteristics of psychologically-relevant referent groups can be a powerful influence. In line with the referent informational influence process, when a particular social identity is salient, people cognitively represent and selfstereotype themselves as ingroup members and their attitudes and behaviors assimilate to the norms of the group. We predicted that messages highlighting promoting ingroup norms favoring water conservation would encourage corresponding behavior change amongst group members. Four studies tested this core hypothesis.

Study 1 provided initial evidence for the effectiveness of an ingroup norms appeal. The observed trend suggested that participants who read about supportive ingroup norms surrounding water conservation subsequently expressed greater intentions to engage in various water saving behaviors compared to those who only received information about the importance of saving water, or no information at all. Study 2 provided initial insight into the underlying mediating process. The intervention tended to enhance perceptions of ingroup water conservation norms and a mediation analysis suggested this strengthening of perceived ingroup norms subsequently initiated a shift in intended behavior. Study 3 then went on to test whether an ingroup norms appeal, focusing on the norms of a specific referent group, would be more effective than a standard social norms-based intervention that focuses on the norms of generalized others. Results support the conclusion that the effectiveness of normative messages increases when emphasis is placed on the referent group attached to the norm, rather than on general social norms. Finally, Study 4 rolled-out this intervention approach in collaboration with the region's water utility company and showed that the 
inclusion of an ingroup norms appeal successfully increased participation in a water efficiency retrofitting program.

Our findings have meaningful implications for the design of environmental campaigns. From a social identity perspective, norms are tied to specific groups, and a norm has its effect because that group is behaviorally-relevant. People are influenced by ingroup norms as they prescribe the context-specific attitudes and behaviors appropriate for group members (Terry \& Hogg, 1996). The implication is that practitioners should focus on the norms of a referent group that is salient in the behavioral context. On the basis of our findings we recommend that campaigns that address local environmental issues should aim to showcase proenvironmental norms (i.e. relating to water conservation) of the group as a defining element of the group identity. Activating the regional identity - such as a local city, neighborhood or community - and communicating credible information about the behavior and practices of ingroup members should strengthen perceived ingroup norms regarding water conservation, resulting in increased water-savings efforts amongst community members.

There are some limitations of the present research that should be acknowledged. Firstly, only marginally significant effects of the intervention were found in Study 1 (in comparison to information-only) and Study 2 (perceptions of ingroup norms). Sample sizes were chosen throughout this investigation to be consistent with other related experimental manipulations of social information (e.g. Masson \& Fritsche, 2014; Rabinovich, Morton, Postmes, \& Verplanken, 2012; Toner et al., 2012). However, in Study 1 and 2 some key effects did not reach conventional levels of significance. We conducted post-hoc analyses in G*Power (Faul, Erdfelder, Lang, \& Buchner, 2007) to find out whether Study 1 and Study 2 had enough power to detect the hypotheses results. In Study 1 the comparison between the ingroup norms condition and the information-only condition only reached marginal 
significance. The effect size of this particular comparison was $d=0.47$. The power to detect an effect of this size in the two present conditions in Study 1 was determined to be 0.73 . In Study 2 the effect of the intervention on perceptions of ingroup norms did not reach full significance. A second power analysis reveals that this comparison $(d=0.32)$ was also underpowered with an observed power of 0.57 . Across all studies, the observed effect sizes are relatively small.This is consistent with prior research on social norms (Fielding et al. 2013; Schultz et al. 2016). It is crucial to acknowledge that such interventions should not be viewed as a panacea to water challenges. Instead, they should be viewed as meaningful addition to the water demand management strategy tool-kit which can be easily integrated into campaign material at little extra cost (Lede \& Meleady, 2019).

Second, it is important to note that only one study reported here included a direct measure of behavior. As is common practice in the field, Study 1 and 2 relied on measures of behavioral intentions, while Study 3 relied on self-reports of recent behavior. There are clear limitations to these methods. Although stating an intention to undertake a behavior is assumed by the TPB to be the most direct psychological determinant of behavior (Ajzen, $1985,1991)$ doing so does not immediately translate to actually undertaking the behavior (intention-behavior gap; Sheeran, 2002). Indeed, Kormos and Gifford (2014) demonstrate that roughly $79 \%$ of the variance between self-reported and objective behavior remains unexplained. Unfortunately, it was not possible to measure actual shower duration in Study 3 and we instead relied on participants' own estimates. While some findings suggests that estimates of time spent in the shower correlate well with measured shower time (Energy Saving Trust, 2013; Mallett \& Melchiori, 2016), others demonstrate that high users think that they are low users, and low users think that they are high users (Beal et al., 2013). Porter, Leeming, and Dwyer (1995) showed that proenvironmental interventions may have stronger effect on self-reported rather than actual behavior. Behavioral effects were however 
confirmed on a direct measure of behavior in Study 4 in the form of sign-ups to a watersaving retrofitting program. We do not, however, have data to confirm whether residents followed through with the program, or whether it led to water-savings. Additionally, the installation of water-efficient technologies may not always lead to optimal water savings because people may compensate by using more water (Geller, Erickson, \& Buttram, 1983). It will be important for future research to consider such potential spillover effects in order to establish the overall total effect of the intervention.

The effectiveness of our ingroup norms appeal was investigated in four studies across three group contexts - a university student group (Studies 1 and 3), a group of city residents (Study 2), and a larger regional group (Study 4). Our evidence suggests that this approach, or variations of it, could be a promising avenue for further investigation. It is worth noting that examination of the baseline survey data (in Study 1 and 2) reveals that water savings intentions were generally above the scale midpoint in all contexts. Further replication in a wider range of populations will therefore be important in order to establish whether there must be some level of environmental concern already present at the collective level for ingroup norms campaigns to be effective. If the desired behavior is not prevalent within the referent group, rather than drawing attention to the negative descriptive norms (e.g. only a minority of local residents engage in water conservation behaviors), it may be possible to place greatest emphasis on a positive injunctive norm (e.g. the majority of local residents support actions that conserve water resources (e.g. Schultz et al., 2007)), or a positive dynamic norm (e.g. in the last month, 30\% of local residents have begun to make an effort to conserve water; Sparkman \& Walton, 2017), thus increasing the applicability of normative campaigns.

Whilst the current studies showed that an information-only message is less effective than an ingroup norms appeal, a certain level of information may be required, if people are 
unsure what the ideal behaviors are, or whether such behaviors are efficacious. Future research can explore the effectiveness of combining ingroup norms appeals with knowledgebased or persuasive appeals. Previously, van der Linden (2015) demonstrated that providing both ingroup normative information (e.g., $65 \%$ of the current students are actively reducing their consumption of bottled water) and information (a one-page persuasive article), reduced intentions to buy bottled water, more than either approach in isolation. Future research may also examine how facilitating proenvironmental behavior can affect attitudes and more generalized behaviors. By providing entering university students with reusable water bottles in conjunction with social norms messaging, Santos and van der Linden (2016), demonstrated increased support for a bottled water ban and decreased bottled water consumption.

It will also be important for explore the boundary conditions of the effects reported here. Research within the social identity approach suggests that the power of group norms to influence the behavior of group members will be strongest for people for whom the salient social identity forms an integral part of their self-concept, that is, for individuals who identify strongly with the group (Abrams \& Hogg, 1990). High, compared to low, levels of identification with the ingroup generally strengthens group-based effects, with individuals who identify strongly with the group being most likely to align their behavior to the group norms (e.g. Fielding et al., 2008; Terry \& Hogg, 1996). Although we present evidence for the superior effectiveness of ingroup norms-based solutions compared to a standard social norms-based approach, the picture may be more complex and moderated by individuals' levels of group identification. Specifically, if identification with a given referent group is low, a more traditional social norms appeal may prove more effective. For people low in identification, appealing to the larger population share adhering to a social norm amongst the general population may prove more persuasive (Lindbeck, Nyberg, \& Weibull, 1999). 
Finally, future research should also consider the role of the intergroup comparative context. The social identity perspective suggests that social categories are understood in comparison to each other (Abrams \& Hogg, 1988; Turner, Oakes, Haslam, \& McGarty, 1994). Individuals strive to differentiate themselves from outgroups in their judgements and in their behavior, and intergroup comparisons are made in a way that maximizes intergroup differences (Oakes, Haslam, \& Turner, 1994). Accordingly, when normative information is provided about individuals from a social outgroup, the behavioral tendency is to engage in the opposite pattern of actions (e.g. Doosje et al,. 1998; Rijswijk, Haslam, \& Ellemers, 2006). This tendency has been documented in the domain of environmental behavior. Rabinovich and colleagues (2012) found that intentions to engage in proenvironmental behavior were weakened when individuals compared their own national group (Britain) to an outgroup with a superior environmental record (Sweden), and strengthened when comparing to an outgroup perceived to be less environmentally conscious (USA, see also Ferguson, Branscombe, \& Reynolds, 2011). While our approach involves crafting normative messages that encourage people to see water conservation as defining of their group (i.e. a positive ingroup norm), another effective approach may be to provide information about negative outgroup stereotypes, eliciting a behavioral contrast effect. Future research should examine how providing information about the wasteful water behaviors of outgroup members may provide a complementary application of social identity principles.

\section{Conclusions}

The present research demonstrates the potential of an ingroup norms appeal to motivate household water conservation behavioral intentions and behavior in a water scarce region. According to the social identity approach, and more specifically, the referent informational influence process, the process of psychologically belonging to a group means that attitudes and behaviors align with the norms advocated by the ingroup. In four studies, 
we show that this process can be harnessed in a message-based campaign to promote household water conservation. An ingroup norms appeal was more effective than providing information alone, or a standard social norms message that neglects ingroup identities.

Results highlight the ways in which the social identity approach can provide critical insights for practitioners seeking to maximize the power of social norms-based interventions and engage communities around water conservation. 


\section{Notes}

${ }^{1}$ Calculated as: 27 (households)x41(liters of water saved per day)]x365(days per year) 


\section{References}

Abrahamse, W., Steg, L., Vlek, C., \& Rothengatter, T. (2005). A review of intervention studies aimed at household energy conservation. Journal of Environmental Psychology, 25(3), 273-291. http://doi.org/10.1016/j.jenvp.2005.08.002

Abrams, D., \& Hogg, M. A. (1988). Comments on the motivational status of self-esteem in social identity and intergroup discrimination. European Journal of Social Psychology, 18(4), 317-334. http://doi.org/10.1002/ejsp.2420180403

Abrams, D., \& Hogg, M. A. (1990). Social identification, self-categorization and social influence. European Review of Social Psychology, 1(1), 195-228. http://doi.org/10.1080/14792779108401862

Abrams, D., Wetherell, M., Cochrane, S., Hogg, M. A., \& Turner, J. C. (1990). Knowing what to think by knowing who you are: Self-categorization and the nature of norm formation, conformity and group polarization*. British Journal of Social Psychology, 29(2), 97-119. http://doi.org/10.1111/j.2044-8309.1990.tb00892.x

Ajzen, I. (1985). From intentions to actions: A theory of planned behavior. In Action control (pp. 11-39). Springer.

Ajzen, I. (1991). The theory of planned behavior. Organizational Behavior and Human Decision Processes, 50(2), 179-211. http://doi.org/10.1016/0749-5978(91)90020-T

Allcott, H. (2011). Social norms and energy conservation. Journal of Public Economics, 95(9-10), 1082-1095. http://doi.org/10.1016/j.jpubeco.2011.03.003

Anglian Water. (2015). Water savings tips. Retrieved March 14, 2016, from http://www.anglianwater.co.uk/environment/how-you-can-help/using-water-wisely/tipshouse/

Anglian Water. (2017). Save bucket loads with a FREE water saving visit. Retrieved October 10, 2017, from https://www.anglianwater.co.uk/environment/how-you-can-help/using- 
water-wisely/we-products/

Asch, S. E. (1955). Opinions and social pressure. Scientific American, 193(5), 31-35. http://doi.org/10.1038/scientificamerican1155-31

Beal, C. D., Stewart, R. a., \& Fielding, K. (2013). A novel mixed method smart metering approach to reconciling differences between perceived and actual residential end use water consumption. Journal of Cleaner Production, 60, 116-128. http://doi.org/10.1016/j.jclepro.2011.09.007

Bonniface, L., \& Henley, N. (2008). 'A drop in the bucket ': Collective efficacy perceptions and environmental behaviour. Australian Journal of Social Issues, 43(3), 345-358.

Burgess, J., Harrison, C. M., \& Filius, P. (1998). Environmental communication and the cultural politics of environmental citizenship. Environment and Planning A, 30(8), 1445-1460. http://doi.org/https://doi.org/10.1068/a301445

Cialdini, R. B., \& Trost, M. R. (1998). Social influence: Social norms, conformity and compliance. In D. Gilbert, S. Fiske, \& G. Lindzey (Eds.), Handbook of social psychology (4th ed., pp. 151-92). Boston: McGraw-Hill.

Committee on Climate Change. (2016). UK Climate Change Risk Assessment 2017. Retrieved from https://www.theccc.org.uk/wp-content/uploads/2016/07/UK-CCRA2017-Synthesis-Report-Committee-on-Climate-Change.pdf

Doosje, B., Haslam, S. A., Spears, R., Oakes, P. J., \& Koomen, W. (1998). The effect of comparative context on central tendency and variability judgements and the evaluation of group characteristics. European Journal of Social Psychology, 28(2), 173-184. http://doi.org/10.1002/(SICI)1099-0992(199803/04)28:2<173::AID-EJSP862>3.0.CO;2Z

Energy Saving Trust. (2013). At home with water. London. Retrieved April 5, 2014, from http://www.energysavingtrust.org.uk/reports/home-water 
Faul, F., Erdfelder, E., Lang, A.-G., \& Buchner, A. (2007). G* Power 3: A flexible statistical power analysis program for the social, behavioral, and biomedical sciences. Behavior Research Methods, 39(2), 175-191.

Ferguson, M. A., Branscombe, N. R., \& Reynolds, K. J. (2011). The effect of intergroup comparison on willingness to perform sustainable behavior. Journal of Environmental Psychology, 31(4), 275-281. http://doi.org/10.1016/j.jenvp.2011.04.001

Fielding, K. S., \& Hornsey, M. J. (2016). A social identity analysis of climate change and environmental attitudes and behaviors: Insights and opportunities. Frontiers in Psychology, 7, 1-12. http://doi.org/10.3389/fpsyg.2016.00121

Fielding, K. S., Spinks, A., Russell, S., McCrea, R., Stewart, R., \& Gardner, J. (2013). An experimental test of voluntary strategies to promote urban water demand management. Journal of Environmental Management, 114, 343-51.

http://doi.org/10.1016/j.jenvman.2012.10.027

Fielding, K. S., Terry, D. J., Masser, B. M., \& Hogg, M. A. (2008). Integrating social identity theory and the theory of planned behaviour to explain decisions to engage in sustainable agricultural practices. British Journal of Social Psychology, 47(1), 23-48. http://doi.org/10.1348/014466607X206792

Freiman, J. A., Chalmers, T. C., Smith, H., \& Kuebler, R. R. (1978). The importance of beta, the type II error and sample size in the design and interpretation of the randomized control trial: Survey of 71 negative trials. New England Journal of Medicine, 299(13), $690-694$.

Fritsche, I., Barth, M., Jugert, P., Masson, T., \& Reese, G. (2017). A Social Identity Model of Pro-Environmental Action (SIMPEA). Psychological Review, 3(August). http://doi.org/10.1037/rev0000090

Geller, E. S., Bechtel, R. B., \& Churchman, A. (2002). The challenge of increasing 
proenvironmental behavior. In Handbook of environmental psychology (Vol. 2, pp. 525540). Wiley.

Geller, E. S., Erickson, J. B., \& Buttram, B. a. (1983). Attempts to promote residential water conservation with educational, behavioral and engineering strategies. Population and Environment, 6(2), 96-112. http://doi.org/10.1007/BF01362290

Goldstein, N. J., Cialdini, R. B., \& Griskevicius, V. (2008). A Room with a Viewpoint: Using Social Norms to Motivate Environmental Conservation in Hotels. Journal of Consumer Research, 35(3), 472-482. http://doi.org/10.1086/586910

Gregory, G. D., \& Leo, M. Di. (2003). Repeated Behavior and Environmental Psychology: The Role of Personal Involvement and Habit Formation in Explaining Water Consumption. Journal of Applied Social Psychology, 33(6), 1261-1296. http://doi.org/10.1111/j.1559-1816.2003.tb01949.x

Griskevicius, V., Cialdini, R. B., \& Goldstein, N. J. (2008). Social norms: An underestimated and underemployed lever for managing climate change. In IJSC (pp. 5-13). Citeseer. Retrieved October 10, 2014, from http://www.ecy.wa.gov/programs/wq/stormwater/municipal/MUNIdocs/SocialNormsRe search.pdf

Hogg, M. A., \& Turner, J. C. (1987). Intergroup behaviour, self-stereotyping and the salience of social categories. British Journal of Social Psychology, 26(4), 325-340. http://doi.org/10.1111/j.2044-8309.1987.tb00795.x

Kahan, D. M., \& Carpenter, K. (2017). Out of the lab and into the field. Nature Clim. Change, 7(5), 309-311. Retrieved from http://dx.doi.org/10.1038/nclimate3283

Kormos, C., \& Gifford, R. (2014). The validity of self-report measures of proenvironmental behavior: A meta-analytic review. Journal of Environmental Psychology, 40, 359-371. Kurz, T., Donaghue, N., \& Walker, I. (2005). Utilizing a social-ecological framework to 
promote water and energy conservation: A field experiment. Journal of Applied Social Psychology, 35, 1281-1300. http://doi.org/10.1111/j.1559-1816.2005.tb02171.x

Lede, E., \& Meleady, R. (2019). Applying social influence insights to encourage climate resilient domestic water behavior: Bridging the theory-practice gap. Wiley Interdisciplinary Reviews: Climate Change, 10(1), e562.

Lindbeck, A., Nyberg, S., \& Weibull, J. W. (1999). Social norms and economic incentives in the welfare state. The Quarterly Journal of Economics, 114(1), 1-35.

Mackie, D., \& Cooper, J. (1984). Attitude polarization: Effects of group membership. Journal of Personality and Social Psychology, 46(3), 575-585. http://doi.org/10.1037/0022-3514.46.3.575

Mallett, R. K., \& Melchiori, K. J. (2016). Creating a water-saver self-identity reduces water use in residence halls. Journal of Environmental Psychology, 47, 223-229. http://doi.org/10.1016/j.jenvp.2016.07.001

Masson, T., \& Fritsche, I. (2014). Adherence to climate change-related ingroup norms: Do dimensions of group identification matter? European Journal of Social Psychology, 44(5), 455-465. http://doi.org/10.1002/ejsp.2036

Morton, T. A., Rabinovich, A., Marshall, D., \& Bretschneider, P. (2011). The future that may (or may not) come: How framing changes responses to uncertainty in climate change communications. Global Environmental Change, 21(1), 103-109.

Nolan, J. M., Schultz, P. W., Cialdini, R. B., Goldstein, N. J., \& Griskevicius, V. (2008). Normative social influence is underdetected. Personality \& Social Psychology Bulletin, 34(7), 913-23. http://doi.org/10.1177/0146167208316691

Oakes, P. J., Haslam, S. A., \& Turner, J. C. (1994). Stereotyping and social reality. Malden: Blackwell Publishing.

OECD. (2012). OECD Environmental Outlook to 2050 : The Consequences of Inaction. 
Retrieved from http://www.oecd-ilibrary.org/environment/oecd-environmental-outlookto-2050_9789264122246-en

Porter, B. E., Leeming, F. C., \& Dwyer, W. O. (1995). Solid waste recovery: A review of behavioral programs to increase recycling. Environment and Behavior, 27(2), 122-152.

Rabinovich, A., Morton, T. a., Postmes, T., \& Verplanken, B. (2012). Collective self and individual choice: The effects of inter-group comparative context on environmental values and behaviour. British Journal of Social Psychology, 51(4), 551-569. http://doi.org/10.1111/j.2044-8309.2011.02022.x

Richetin, J., Perugini, M., Mondini, D., \& Hurling, R. (2016). Conserving water while washing hands: The immediate and durable impacts of descriptive norms. Environment and Behavior, 48(2), 343-364. http://doi.org/10.1177/0013916514543683

Rijswijk, W., Haslam, S. A., \& Ellemers, N. (2006). Who do we think we are? The effects of social context and social identification on in-group stereotyping. British Journal of Social Psychology, 45(1), 161-174. http://doi.org/10.1348/014466605X39475

Santos, J. M., \& van der Linden, S. (2016). Environmental Reviews and Case Studies: Changing Norms by Changing Behavior: The Princeton Drink Local Program. Environmental Practice, 18(2), 116-122

Schultz, P. W. (2002). Knowledge, information, and household recycling: Examining the knowledge-deficit model of behavior change. In T. Dietz \& P. C. Stern (Eds.), New tools for environmental protection: Education, information, and voluntary measures (pp. 6782). Washington: The National Academies Press http://doi.org/https://doi.org/10.17226/10401

Schultz, P. W., Messina, A., Tronu, G., Limas, E. F., Gupta, R., \& Estrada, M. (2016). Personalized Normative Feedback and the Moderating Role of Personal Norms: A Field Experiment to Reduce Residential Water Consumption. Environment and Behavior, 
48(5), 686-710. http://doi.org/10.1177/0013916514553835

Schultz, P. W., Nolan, J. M., Cialdini, R. B., Goldstein, N. J., \& Griskevicius, V. (2007). The constructive, destructive, and reconstructive power of social norms. Psychological Science, 18(5), 429-434. http://doi.org/10.1111/j.1467-9280.2007.01917.x

Seyranian, V. (2014). Social identity framing communication strategies for mobilizing social change. The Leadership Quarterly, 25(3), 468-486.

http://doi.org/10.1016/j.leaqua.2013.10.013

Seyranian, V., Sinatra, G. M., \& Polikoff, M. S. (2015). Comparing communication strategies for reducing residential water consumption. Journal of Environmental Psychology, 41, 81-90. http://doi.org/10.1016/j.jenvp.2014.11.009

Sheeran, P. (2002). Intention-behavior relations: A conceptual and empirical review. European Review of Social Psychology, 12(1), 1-36.

Sherif, M. (1936). The psychology of social norms. The psychology of social norms. Oxford, England: Harper.

Simon, B., \& Hamilton, D. L. (1994). Self-stereotyping and social context: The effects of relative in-group size and in-group status. Journal of Personality and Social Psychology, 66(4), 699-711. http://doi.org/10.1037/0022-3514.66.4.699

Sinclair, M., O’Toole, J., Malawaraarachchi, M., \& Leder, K. (2012). Comparison of response rates and cost-effectiveness for a community-based survey: postal, internet and telephone modes with generic or personalised recruitment approaches. BMC Medical Research Methodology, 12(1), 132. http://doi.org/10.1186/1471-2288-12-132

Sønderlund, A. L., Smith, J. R., Hutton, C. J., Kapelan, Z., \& Savic, D. (2016). Effectiveness of smart meter-based consumption feedback in curbing household water use: Knowns and unknowns. Journal of Water Resources Planning and Management, 142(12), 4016060. 
Sparkman, G., \& Walton, G. M. (2017). Dynamic Norms Promote Sustainable Behavior , Even if It Is Counternormative. Psychological Science, 28(11), 1663-1674. http://doi.org/10.1177/0956797617719950

Steg, L., \& Vlek, C. (2009). Encouraging pro-environmental behaviour: An integrative review and research agenda. Journal of Environmental Psychology, 29(3), 309-317. http://doi.org/10.1016/j.jenvp.2008.10.004

Syme, G. J., Nancarrow, B. E., \& Seligman, C. (2000). The evaluation of information campaigns to promote voluntary household water conservation. Evaluation Review, 24(6), 539-578. http://doi.org/10.1177/0193841X0002400601

Tajfel, H., \& Turner, J. C. (1979). An integrative theory of intergroup conflict. The Social Psychology of Intergroup Relations, 33(47), 74.

Tajfel, H., \& Turner, J. C. (1986). The social identity theory of inter group behavior in S Worchel \& WG Austin (Eds) Psychology of intergroup relations. Chicago: Nelson.

Terry, D. J., \& Hogg, M. A. (1996). Group Norms and the Attitude-Behavior Relationship: A Role for Group Identification. Personality and Social Psychology Bulletin, 22(8), 776793. http://doi.org/10.1177/0146167296228002

Terry, D. J., Hogg, M. A., \& McKimmie, B. M. (2000). Attitude-behaviour relations: the role of in-group norms and mode of behavioural decision-making. British Journal of Social Psychology, 39(3), 337-361. http://doi.org/10.1348/014466600164534

Terry, D. J., Hogg, M. A., \& White, K. M. (1999). The theory of planned behaviour : Selfidentity, social identity and group norms. British Journal of Social Psychology, 38(3), 225-244. http://doi.org/10.1348/014466699164149

Toner, K., Gan, M., \& Leary, M. R. (2012). The Impact of Individual and Group Feedback on Environmental Intentions and Self-Beliefs. Environment and Behavior, 46(1), 24-45. http://doi.org/10.1177/0013916512451902 
Turner, J. C. (1982). Towards a cognitive redefinition of the social group. (H. Tajfel, Ed.)Social identity and intergroup relations. Cambridge: Cambridge University Press Cambridge (UK).

Turner, J. C., Hogg, M. A., Oakes, P. J., Reicher, S. D., \& Wetherell, M. S. (1987). Rediscovering the social group: A self-categorization theory. Cambridge, MA, US: Basil Blackwell.

Turner, J. C., Oakes, P. J., Haslam, S. A., \& McGarty, C. (1994). Self and collective: Cognition and social context. Personality and Social Psychology Bulletin, 20(5), 454463. http://doi.org/10.1177/0146167294205002

Turner, J. C., \& Reynolds, K. J. (2008). The social identity perspective in intergroup relations: Theories, themes, and controversies. In R. Brown \& S. Gaertner (Eds.), Blackwell handbook of social psychology: Intergroup processes (pp. 133-152). John Wiley \& Sons Inc.

Turner, J. C., Wetherell, M. S., \& Hogg, M. A. (1989). Referent informational influence and group polarization. British Journal of Social Psychology, 28(2), 135-147.

http://doi.org/10.1111/j.2044-8309.1989.tb00855.x

UEA. (2016). UEA 2016 Annual Environmental Report. Norwich. Retrieved March 14, 2017 , from http://www.uea.ac.uk/documents/3154295/9533899/2016+Annual+Environmental+Rep ort_web.pdf/

Van Der Linden, S. (2015). Exploring beliefs about bottled water and intentions to reduce consumption: The dual-effect of social norm activation and persuasive information. Environment and Behavior, 47(5), 526-550.

World Economic Forum. (2015). Global Risks 2015: 10th Edition. Retrieved May 5, 2016, from http://www3.weforum.org/docs/WEF_Global_Risks_2015_Report15.pdf 
